\title{
Cognitive Dissonance of Graduate Students During Clinical Sessions of a Literacy Program: Types of Episodes and their Resolution
}

Pam Britton Reese

Purdue University Fort Wayne, reesepg@pfw.edu

Ludwika Aniela Goodson

Education Consultant and former Associate Director, Center for the Enhancement of Learning and Teaching, Purdue University Fort Wayne, ludygood@gmail.com

DOI: https://doi.org/10.30707/TLCSD3.2Reese

Follow this and additional works at: https://ir.library.illinoisstate.edu/tlcsd

Part of the Educational Methods Commons, Educational Psychology Commons, Language and Literacy Education Commons, Other Teacher Education and Professional Development Commons, Scholarship of Teaching and Learning Commons, and the Speech Pathology and Audiology Commons

\section{Recommended Citation}

Britton Reese, Pam and Aniela Goodson, Ludwika (2019) "Cognitive Dissonance of Graduate Students During Clinical Sessions of a Literacy Program: Types of Episodes and their Resolution," Teaching and Learning in Communication Sciences \& Disorders: Vol. 3: Iss. 2, Article 5.

DOI: https://doi.org/10.30707/TLCSD3.2Reese

Available at: https://ir.library.illinoisstate.edu/tlcsd/vol3/iss2/5

This Scholarship of Teaching and Learning Research is brought to you for free and open access by ISU ReD: Research and eData. It has been accepted for inclusion in Teaching and Learning in Communication Sciences \& Disorders by an authorized editor of ISU ReD: Research and eData. For more information, please contact ISUReD@ilstu.edu. 


\title{
Cognitive Dissonance of Graduate Students During Clinical Sessions of a Literacy Program: Types of Episodes and their Resolution
}

\author{
Abstract \\ This study provided an authentic context for examining cognitive dissonance of graduate students who \\ were learning clinical skills in a six-week language and literacy project designed for young children. These \\ student-clinicians received instruction four days a week in classroom sessions and began clinical \\ sessions with children after each class. Signature pedagogies in communication sciences and disorders \\ (CSD) provided the foundation for the instruction and clinical supervision. In their sessions with the \\ children, the student-clinicians were expected to apply knowledge gained from the classroom and \\ supervisor guidance. Journal entries, supervisor notes, clinical observation records, and transcripts from \\ interviews were coded for factors involved in identifying and resolving cognitive dissonance: perception, \\ difficulty, resistance, reflection, critical thinking, and guidance. Results identified types of cognitive \\ dissonance and factors involved in resolving this dissonance. This study includes recommendations for \\ similar CSD programs for changes in assessment of student entry-skills, instruction, supervision, and \\ reflective practice.

\section{Keywords} \\ cognitive dissonance, clinical education, clinical practice, reflection strategies, supervisor guidance; \\ signature pedagogy; communication sciences and disorders, student-clinicians

\section{Cover Page Footnote} \\ Pam Britton Reese conducted the original research as part of a literacy program at the University of \\ Louisiana at Lafayette. At Purdue University Fort Wayne, she collaborated with Ludwika Aniela Goodson \\ to review and analyze the data on cognitive dissonance. Send correspondence concerning the literacy \\ program and this research to ludygood@gmail.com or reesepg@pfw.edu.
}




\section{Introduction}

Festinger (1957), who formulated the cognitive dissonance theory, proposed that individuals seek to avoid tension or dissonance between concepts they hold and will make adjustments to reduce conflict and re-establish equilibrium. This theory has relevance for communication sciences and disorders (CSD) because cognitive dissonance can affect the quality and direction of thinking which ultimately can influence clinical decisions and strategies. Some of the influences in the clinical-teaching context may be internal cognitions, such as, prior knowledge, critical thinking, or preheld beliefs. Others may be external and unique to the clinical-teaching context, such as the complexity or difficulty of client needs, the kind of instruction received, or the type of supervision provided. Student-clinicians often experience heightened anxiety and challenges when they encounter conflicts between concept knowledge gained from classroom instruction and applying such knowledge in a clinical context (Brackenbury, Folkins, \& Ginsberg, 2014; Dean \& Jolly, 2012; Dutton, \& Sellheim, 2017). They also may experience greater conflict if they think they are not doing what they expect to do as compared to their own expectations or those of friends, family or groups with which they hold affiliation (Cooper, 2007).

In spite of the unsettling quality of cognitive dissonance, it frequently benefits student-clinicians because it activates critical reflection, which then produces changes in beliefs and improves future clinical-teaching practices (Barron, 2015; Folkins, 2016; Gay, 2010). The dissonance tends to engage skepticism, curiosity, questioning of ideas and alternative views, prompting students to search for information to better understand a situation - all of which characterize critical thinking (Atabaki, Keshtiaray, \& Yarmohammadian, 2015; Lai, 2011; Patrick, 1986). In CSD pedagogy, the quality of reflective practice supports deeper learning and clinical thinking (Brackenbury et al., 2014). Difficulties arise in resolving cognitive dissonance when a student lacks critical thinking skills, resists change, or finds the cognitive load too overwhelming in learning or clinical practice (Cane, Ferguson, \& Apperly, 2017; Durden \& Truscott, 2013; Folkins, 2016; Gerjets, Scheiter, \& Cierniak, 2009; Hart et al., 2009; Van Merriënboer \& Sweller, 2005).

Figure 1 provides a visual display of major factors from the literature review that seem to have an impact on an individual's capability to identify and resolve cognitive dissonance. Perception of an inconsistency between any of the internal cognitions and dispositions, and the reality of the clinical-teaching context may be thought of as the starting point for cognitive dissonance. Perception of conflicts, resistance to change, and difficulty of choices interact in complex ways to influence awareness of cognitive dissonance, and can increase or diminish the motivation to make any changes. 


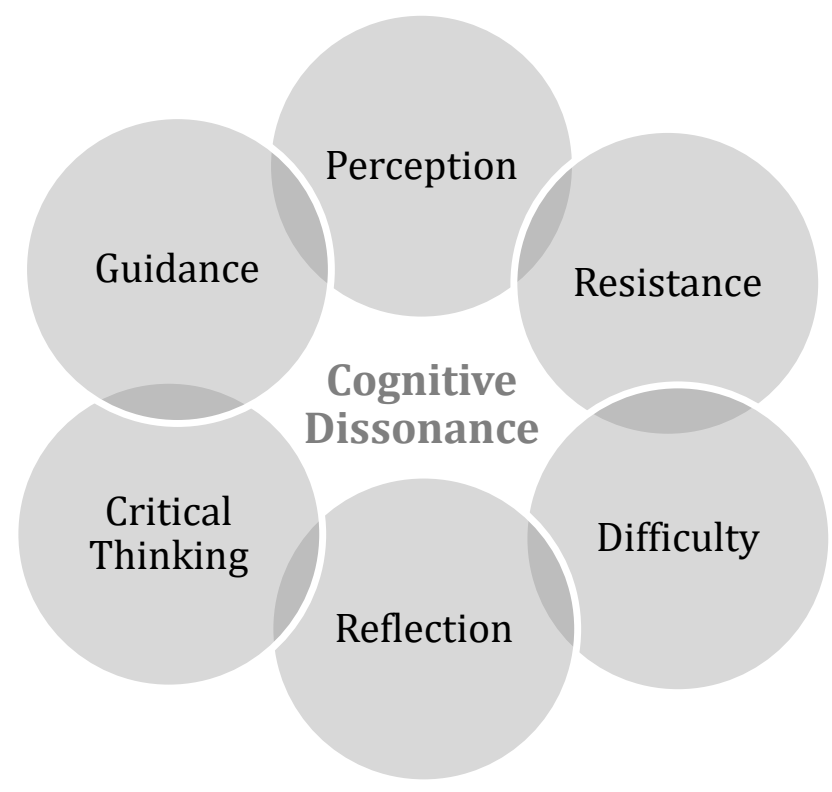

Figure 1. Factors that have an impact on the capability to identify and resolve cognitive dissonance

The factors interacting in perceiving and resolving cognitive dissonance are not mutually exclusive and one factor can interplay with the other. For example, reflection can reveal difficulty and prompt critical thinking or a request for guidance. Although the dynamics of instruction, clinical supervision, and client needs may be expected to change an individual's knowledge, beliefs, or process of thinking, such change may not occur when prior knowledge, beliefs, or thinking processes remain entrenched in the status quo. Student-clinicians are likely to be motivated to change their thinking and clinical practice only when their awareness of inconsistencies in their attitudes, beliefs, values, behaviors, or knowledge becomes unsettled enough to pull decisions and actions in opposite directions (Berlyne, 1965; Festinger, 1957; McGregor, Newby-Clark, \& Zanna, 1999; McLeod, 2018; Rolls, 2015). Then, after making a decision, reflection may lead to questions, such as "Why did I do what I did?" or "Should I keep doing it?"

Accurate perception enables awareness of conceptual conflicts, helps to frame the problems that arise in clinical practice, and influences strategies for resolution (Glaser, 1942; Wright, Rutgers, Daly, Jablokow, \& Yilmaz, 2015). Although critical, this perception can be obscured or distorted with incomplete observations, prejudices, or logical errors (Glaser, 1942; Wright et al., 2015). How to activate perception is one of the challenges for the instruction-to-clinical practice setting. Yet, regardless of accurate perception, student-clinicians may have resistance to change.

The literature on cognitive dissonance indicates that resistance can be grounded in a high tolerance for ambiguity and conflict (Cooper, 2007; Walton, 2011; Wicklund \& Brehm, 1976), rationalizing of a behavior or denying responsibility (Dean \& Jolly, 2012; Folkins, 2016; Pychyl, 2011), placing self- and vested-interests as a greater priority (Cane, et al., 2017; Festinger, 1957; Jost, 2015; Wicklund \& Brehm, 1976), trivializing the importance of dissonance or seeking distractions from it (Dean \& Jolly, 2012; Mills, 1999; Pychyl, 2011), or seeing no way to make a change or fearing 
a change will be irreversible (Burnes, 2015; Festinger, 1957; Wicklund \& Brehm, 1976). Resistance can persist even after an individual is given negative feedback that supports a change in perception (Jermias, 2001).

Another factor affecting decisions about what or how to change is the difficulty of the choices (McLeod, 2018). For example, in the CSD clinical context, a student-clinician might be able to make simple adjustments to the strategies for a child who already reads fluently, but could be more perplexed about what strategies to use when working with a child who pulls off a cochlear implant during a shared-reading session. Difficulty may increase further with the cognitive load of complex problems or the intensity of dueling concepts, such as perception of a child's needs vs. the desire to follow a prescribed clinical protocol that does not seem to fit those needs (Berlyne, 1965; Firestone, 2004; Folkins, 2016; Harmon-Jones, Harmon-Jones, \& Levy, 2015; Hirsh, Galinsky, \& Zhong, 2011; Jonassen, 2012; McFall, 2015; McNamee \& Celona, 2008; Tolsgaard, Kulasegaram, \& Ringsted, 2016; Walton, 2011). Even for difficult choices, justification may follow as this often provides a sense of self-protection (Lee \& Schwarz, 2010; Stone, \& Focella, 2011; Wong, 2009).

In contrast to the barriers for perception and resolution of cognitive dissonance, reflective thinking and guidance typically produce the necessary incentives to change behaviors and are commonly used strategies for teaching clinical practices. In fact, reflective practice is an integral aspect of the signature pedagogy in CSD (Brackenbury et al., 2014; Tillard, Cook, Gerhard, Keast, \& McAuliffe, 2018). It is the practice of thinking about personal experiences in order to improve the process and outcomes of professional practice with the goal of continual improvement, which is critical for developing clinical competence (Hill, Davidson, \& Theodoros, 2012). The Council on Academic Accreditation in Audiology and Speech-Language Pathology (CAA), a semiautonomous body of the American Speech-Language-Hearing Association (ASHA), includes clinical thinking, self-reflection, and clinical judgment skills essential in real-world clinical practice in the professional practice competencies expected for student-clinicians (ASHA, n.d.; Brackenbury et al., 2014; CAA, 2017; Folkins, 2016). This reflective practice provides a structured opportunity for higher-level thinking, deeper understanding, evaluation of evidence, and reasoning about judgments (Clydesdayle, 2016; Hargreaves, 2016; Solis, 2015). For this reason, students may benefit more from opportunities to engage in reflective practice experiences, encouragement of deep rather than surface learning, and deliberate development of their critical thinking skills over time (ASHA, n.d.; Folkins, 2016). Reflective practice may occur during and after clinical sessions in various activities, such as peer discussions, supervisor guidance, or during reflective writing in journals (Caty, Kinsella, \& Doyle, 2014; Dyment \& O'Connell, 2014; Lew \& Schmidt, 2011; McSweeney, 2014; Tillard, et al., 2018).

As long as flawed logic or fixed habits of thinking do not get in the way, a body of evidence shows us that reflective thinking enables the self-evaluation of learning and improves future thinking, reasoning, and connections with new ideas or alternative ways of thinking (Brandes \& Boskic, 2008). This process supports perception of conceptual conflicts, the interpretation of dilemmas, and thinking about how to cope with difficult choices, all of which promote rapid and precise clinical decisions and post-decision reflections (Jost, 2015; Rauch \& Scheming, 2010; Sinclair, 2009). It also improves self-regulation and metacognitive thinking about what skills to use, thereby, reducing the difficulty of deciding among competing alternatives (Nilson, 2013; Panadero \& Alonso-Tapia, 2014). 
Guidance in the form of encouragement and ideas for reframing or interpreting knowledge can increase awareness of cognitive dissonance and resolve ambiguities (Cane, et al., 2017; Palloff \& Pratt, 2007). It often comes in the form of hints, questions, demonstrations or modeling, additional information, peer tutoring, and feedback. Guidance may come from credible experts, peers, teachers, and self-reflection (Fani \& Ghaemi, 2011; Jost, 2015; McKimmie, Terry, \& Hogg, 2009). Students should receive just enough guidance so that they learn to complete tasks independently, and after successful accomplishment are able to go to the next level of more complex learning tasks (Wass \& Golding, 2014). This approach approximates Anderson's continuum of supervision (Anderson, 1988; Harris et al., 1992). At the proximal stage of development-somewhere between the ability to work only with complete guidance and the ability to work independently - guidance and encouragement will support thinking and learning (Fani \& Ghaemi, 2011; Roberson, 2017; Vygotsky, 1978). Outside of this zone, it may have little or no impact. Similarly, when clinical supervisors explicitly tell students what to do, they diminish the need for reflection (Folkins, 2016).

In summary, the factors of perception, resistance, difficulty, reflection, critical thinking, and guidance may influence the identification and resolution of cognitive dissonance that CSD students experience as they transition from classroom instruction to clinical practice. In this context, the present study sought answers to the following research questions: What types of cognitive dissonance do the student-clinicians experience? And, what factors interact to identify and resolve their cognitive dissonance?

\section{Methodology}

Language and Literacy Activities. Twelve graduate students (nine females and three males) participated in a literacy project that provided the context for this study. They were in a CAA accredited master's program in Speech-Language Pathology. They were enrolled in a literacy course that required six weeks of classroom instruction and a concurrent six weeks of participation in clinical sessions designed to improve the language and literacy skills of young children. In this literacy project context, the student-clinicians experienced a variation of the signature pedagogy of a theory-first practice followed by reflective practice, similar to service learning and providing them with many hands-on opportunities (Brackenbury et al., 2014). In other words, after completing instruction in separate courses, students did not experience an abrupt leap into an intensive clinic workload with little or no previous experience. Instead, in this literacy project, they experienced a series of clinical practice sessions after each of the ongoing classroom sessions. This design of parallel clinical practices provided the graduate students with the opportunity to make more connections of clinical practice with their knowledge of the theories presented in the classroom.

Before beginning the literacy project, these student-clinicians attended a week of classes and received an orientation to the project. Orientation included the schedule and video examples of children in reading sessions who had been in a previous literacy project. The student-clinicians contacted the families of the 24 children participating in the project to set a schedule for assessment. They then assessed each child's entry-level skills. The classroom instruction to prepare student-clinicians for their clinical sessions included models of expected clinical practice. This instruction was provided in a 4-day Monday-Thursday schedule from 7:45 AM to 9:15 AM. 
The classroom instructor for the project was the department's eminent scholar in CSD, who had met the university's qualifications for professorship, including Ph.D. status with research and publications related to the CSD field of study. After each class period, the student-clinicians walked over to another building that had a large meeting space for whole group sessions and separate small offices for shared reading sessions. Their clinical sessions with the children were scheduled from 10:00 AM to 12:15 PM.

At 10:00 AM, the children began their check-in with a few minutes for silent reading or writing in their dialogue journals. After this check-in time, they participated in whole group reading, shared reading, and small group sessions with the graduate student clinicians until 11:15 AM. Next, the children had a "snack time" break with more time for silent reading or writing in dialogue journals. Their last activity from 11:40 AM to 12:15 PM was the writing workshop (based on Calkins, 1994, 2006) which included shared or guided writing. The first four weeks of the project continued with this core set of clinical activities. The final two weeks integrated "special days" (i.e., Pirate Day and Pajama Day) and the clinical supervisors scaled back on the guidance provided. Celebration activities (i.e., an award ceremony and birthday party) took place on the last day of the project. In keeping with a weekly reflective practice, the graduate students were instructed to think and write in their reflection journals about connections they were seeing between their clinical experiences and the classroom instruction, their challenges, and possible solutions. In addition, they were instructed to write in the anecdotal journals an assessment of each child's literacy.

Three speech-language pathologists served as clinical supervisors and provided additional instruction and guidance. As required by the university, each supervisor had at least a Master's degree and certificate of clinical competence from ASHA, with one having a Ph.D. as well. Professional guidelines and project protocols guided the supervisor role: model best clinical practices, analyze and evaluate student-clinician performance, give guidance to support student self-reflection on strategies and achievement of clinical goals, and connect academic knowledge to clinical practice (ASHA, 2013; Council of Academic Programs in Communication Sciences and Disorders, 2013). The supervisors did not receive any specialized training for how to provide guidance in this project. The instructor for the classroom sessions provided consultation to one student during the project. Otherwise, the three clinical supervisors provided guidance with each one assigned to supervise two to five students.

Data Records. The study used a wide range of data sources (see Appendix for examples) — clinical observation notes, transcriptions of interviews, anecdotal and reflection journals, and supervisor feedback forms - to capture a broad range of information (Corbin \& Strauss, 2015). By using these multiple sources close to the students' and supervisors' clinical context, the data yielded more complete and authentic qualitative data than would have been provided from a single perspective (Corbin \& Strauss, 2015; Creswell, 2013; Damico \& Ball, 2010; Damico, Simmons-Mackie, Oelschlaeger, Elman \& Armstrong, 1999; Sawchuk, 2013; Strayhorn, 2006; Yeasmin \& Rahman, 2012). For supervisors, data sources included field notes taken during all daily project activities, transcriptions of videotapes and audiotapes, clinical notes made on the daily Supervisor Feedback form, and comments in students' journals or anecdotal records. The field notes recorded the presence or absence of modeling during the shared reading sessions in which supervisors interacted with the graduate students. 
The first author interviewed all but one of the student-clinicians and all the supervisors in order to gain insight into their respective experiences. The interviews were recorded and transcribed for data analysis. The student-clinicians were interviewed during the week after the literacy project ended, and the supervisors were interviewed two to three weeks after the conclusion of the project. Open questions book-ended each interview. For graduate students, the interviewer began by asking: "Is there anything in particular you would like to talk about concerning your literacy project experiences?" Other questions followed, including: "Were you able to use any information from the Language and Literacy class in the literacy project?"; "How do your thoughts and feelings at the end of the project compare to your thoughts and feelings at the beginning of the project?"; and "Is there anything else you would like to tell me about your literacy project experience?"

For supervisors, the interviewer began by asking: "Is there anything in particular you would like to talk about concerning the literacy project and supervision?" Other questions followed, including: "How many students were concerned enough about something to make an appointment with you in your office?"; "What do you do with students who are struggling?"; "Let's talk a bit about student reflections."; "What about students who don't 'reflect' well?"; "How do you guide them to reflect, rather than describe anecdotes?"; and "Is there anything else you would like to tell me about the literacy project experience?"

Data Analysis Procedures. In the first stage of analysis, both investigators searched for lines of text from the data records that expressed conflicts in thinking, uncertainty about the reasons for clinical decisions or strategies, confusion about instruction compared to practice, questions about whether to keep using the same strategies, and exploration of what strategies might work better in future clinical sessions. The investigators first searched for statements of concern or uncertainty about decisions and conflicts because this is the stage at which thinking is pulled in opposite directions and cognitive dissonance begins (Berlyne, 1965). For those data sets, the investigators then met to discuss agreements, disagreements, and resolve differences in their analysis.

In the second stage of analysis, the investigators used the cognitive dissonance factors from the literature review (see Figure 1) to code the identified conceptual conflicts and further examined the data sets to identify patterns of text indicating perception of dissonance, resistance to change, difficulty of clinical challenges, reflection or critical thinking about the dissonance or resolution strategies, and presence of or response to guidance.

During once-a-week meetings for three weeks, the investigators discussed concepts emerging in the data sets and made preliminary decisions on how to code them. After independently coding data, they compared their decisions and resolved a couple of differences through further discussion in a two-day writing institute. Generally, 1-5 lines of text from the data sources contained one or more of the factors. Table 1 provides examples for each factor.

In periodic follow-up meetings, the investigators repeated the cycle of comparing their coding of data sets. They coded supervisor guidance by using the four identifiers of feedback, modeling, encouragement, and face-to-face guidance. Table 2 provides descriptions and examples of each type of supervisory guidance. 
Table 1.

Examples of coding for graduate students' cognitive dissonance

Code: Perception of cognitive dissonance: Expressed awareness of a discrepancy between clinical thinking or action and recommendations from instruction, a supervisor, or external source (including statements of confusion, doubt, uncertainty, or a plea for help).

Example: "...I didn't know if I've done the right thing, if I said the right thing...like he [the instructor] didn't get to intervention until the last couple of weeks... looking back it was like "oh, maybe I should've done that or coulda said those things"

Code: Resistance to change: Action of noncompliance or expression of a refusal to accept or comply with recommendations from instruction or supervisor guidance.

Example: “... there's so much debate and it seems like such a tense thing to go into. My mom does early intervention specialist, just a couple of conversations I've had with her about it has just been tense and so I just, like, ohhh, just like, I don't want to mess with it..."

Code: Difficulty of deciding among competing alternatives: Expressed complexity or challenge in thinking about the push-pull between competing concepts or strategies.

Example: "I feel like I'm denouncing the Literacy Gods when my first instinct is to teach finger tracking, or to say words so slow that you're forced to hear each phoneme...Everything I've learned is telling me not to do the things I want to do most..."

Code: Reflection about aspects of the cognitive dissonance or guidance received. Expressed consideration of what may be involved in the challenges of clinical sessions.

Example: "Playing around w/sound-letter stuff Really does just fall out of good literacy and exposure. Maybe he's been doing that for a while - but is never done it w/me. He did it in writing time- 'Water. Wa-wa-water' + again in reading multiple times. Now I know he's thinking about the print..."

Code: Critical Thinking to analyze cause and effect or potential solutions. Expressed extended thinking of causes, effects, or possible solutions for dissonance.

Example: “...My whole intervention was based on getting his [the child's] attention to the print and using it as, as a cue to help him figure out what the stories are about. Because he's very good at telling stories and understanding stories and, um, he doesn't have any problems with those kinds of things. So once he can get himself access to the print then he's kind of good to go. So, I did a lot of, lots of shared reading, lots of repetitive books..."

Code: Guidance to support resolution: Record of guidance provided from a supervisor to support resolution of dissonance.

Example: "Today I also waited beyond when it seemed uncomfortable. [The child] needs to discover that reading can be fun and enjoyable much like Ohanian discusses in "Reading for What?"... I would like to find a way to bring this into group...I am going to spend time this weekend working on ways to make our group more cohesive." [Supervisor had written in journal: "keep inviting into interesting + meaningful interactions... I can give you some references. Or you can search Johnson+ Johnson...”] 
Table 2.

Examples of coding for supervisory guidance

Code: Feedback. Contextualized evaluative, directive, informative guidance, often to link the class to the clinic, verify a strategy, highlight key issues, or ask extending questions.

Example: "...One of her concerns is vocabulary-does your material support this? How do you address any unfamiliar or potentially unfamiliar vocab.? Your own fluency/intonation while reading needs to be emphasized." [A supervisor's note in a student's journal.]

Code: Modeling. Demonstration of clinical teaching strategies such as modeling mediating during shared reading, using reading and writing strategies.

Example: "[The supervisor] entered the room and modeled, for the clinician, mediation and a shared reading activity..." [A clinical observation recorded by the clinical investigator.]

Code: Encouragement. Prompting or motivational words for the student to use certain techniques, to extend thinking, or to continue a course of action or reflection.

Example: "That happens. Re-group and move on."

Code: Face-to-face. A meeting of the supervisor with a graduate student, generally in the hall after the shared session had ended, or in the supervisor's office (these meetings could be expected to include any strategies, but recordings were not made and are not part of the project's artifacts).

Example: "I know that [graduate student] came to see me a couple of times and I can't remember if it was in direct conjunction with..." [An interview transcript.]

\section{Results}

\section{Presence of Cognitive Dissonance}

A total of 393 lines out of 4,543 lines of text (9\%) contained phrases or statements indicating the presence of cognitive dissonance, and an equal number appeared in the reflection journals (186 of 1082 lines) and interview transcripts (186 of 3094 lines) (see Table 3). This count reveals that nearly three times as many cognitive dissonance lines appeared in the reflection journals (17\%) as compared to the anecdotal journals (6\%) and to the interview transcripts $(6 \%)$.

The number of lines of recorded reflections and the number of cognitive dissonance lines varied across the three supervisor groups, with each supervisor having a different number of students assigned for clinical supervision. Supervisor A had four students, Supervisor B had five, and Supervisor C had two. Students of Supervisor A expressed cognitive dissonance in 165 of 2124 (8\%) lines of text compared to 67 of 1319 (5\%) for students of Supervisor B, and 161 of 1100 $(15 \%)$ for students of Supervisor C. This data shows the percent of cognitive dissonance lines was almost two times as many for Supervisor C's students compared to Supervisor A and three times as many compared to Supervisor B. Table 4 shows the overall count distributed among reflection journals, anecdotal journals, and interview transcripts for each of the three supervisors. 
Table 3.

Overall count of cognitive dissonance

\begin{tabular}{cccc}
\hline \multicolumn{1}{c}{ Data Source } & $\begin{array}{c}\text { Count of Cognitive } \\
\text { Dissonance }\end{array}$ & $\begin{array}{c}\text { Total Lines } \\
\text { in Data Records }\end{array}$ & $\begin{array}{c}\text { Percent of Cognitive } \\
\text { Dissonance }\end{array}$ \\
\hline Reflection Journals & 186 & 1082 & $17 \%$ \\
\hline Anecdotal Journals & 21 & 367 & $6 \%$ \\
\hline Interview Transcripts & 186 & 3094 & $6 \%$ \\
\hline \multicolumn{1}{c}{ Overall } & 393 & 4543 & $9.0 \%$ \\
\hline
\end{tabular}

Table 4.

Cognitive dissonance for students per supervisor

\begin{tabular}{cccc}
\hline Supervisor & $\begin{array}{c}\text { Count of Cognitive } \\
\text { Dissonance }\end{array}$ & $\begin{array}{c}\text { Total Lines } \\
\text { in Data Records }\end{array}$ & $\begin{array}{c}\text { Percent of Cognitive } \\
\text { Dissonance }\end{array}$ \\
\hline Supervisor A & 165 & 2124 & $8 \%$ \\
\hline Supervisor B & 67 & 1319 & $5 \%$ \\
\hline Supervisor C & 161 & 1100 & $15 \%$ \\
\hline Overall & 393 & 4543 & $9.0 \%$ \\
\hline
\end{tabular}

The total number of data sets for this study was eleven because one of the twelve student-clinicians in the literacy project had been assigned to work with children who had already demonstrated successful reading skills and whose data records were too few for analysis. For data records of the eleven remaining student-clinicians, the count of cognitive dissonance lines ranged from a low of 0 to a high of 90 , but the percentages ranged from a low of $0 \%$ to a high of $22 \%$ as shown in the "Data Totals" column of Table 5. The lines of text reported in the "Lines" column in Table 5 indicate cognitive dissonance lines out of the total number of lines in the data set for the individual student-clinicians. For example, under the "Data Totals" column, the GS 8 totals of 0/414 indicate zero lines of dissonance out of a total of 414 lines (0\%), the GS 4 totals of 25/889 indicate 25 lines of dissonance out of a total of 889 lines (3\%), and the GS 9 totals of 17/374 indicate 17 lines of dissonance out of a total of $374(5 \%)$.

In addition, the data reported in Table 5 shows that the number of total lines of text may indicate more reflection, but this does not necessarily align with more cognitive dissonance. For example, GS 4's data set had 889 lines of which only 25 (3\%) expressed cognitive dissonance; whereas GS 11 's data set had 465 lines of which 90 (19\%) expressed cognitive dissonance. 
Table 5.

Cognitive dissonance organized from 0 to $22 \%$ out of total number of lines in data records.

\begin{tabular}{|c|c|c|c|c|c|c|c|c|}
\hline & \multicolumn{2}{|c|}{ Interview Transcript } & \multicolumn{2}{|c|}{ Reflection Journal } & \multicolumn{2}{|c|}{ Anecdotal Journal } & \multicolumn{2}{|c|}{ Data Totals } \\
\hline & Lines & Percent & Lines & Percent & Lines & Percent & Lines & Percent \\
\hline GS 8 & $0 / 297$ & $0 \%$ & $0 / 100$ & $0 \%$ & $0 / 17$ & $0 \%$ & $0 / 414$ & $0 \%$ \\
\hline GS 4 & $7 / 554$ & $1 \%$ & $17 / 315$ & $5 \%$ & $1 / 20$ & $5 \%$ & $25 / 889$ & $3 \%$ \\
\hline GS 9 & $0 / 264$ & $0 \%$ & $17 / 83$ & $21 \%$ & $0 / 27$ & $0 \%$ & $17 / 374$ & $5 \%$ \\
\hline GS 5 & $16 / 235$ & $7 \%$ & $10 / 103$ & $10 \%$ & $1 / 42$ & $2 \%$ & $27 / 380$ & $7 \%$ \\
\hline GS 3 & $29 / 341$ & $9 \%$ & $0 / 0$ & $0 \%$ & $3 / 44$ & $7 \%$ & $32 / 385$ & $8 \%$ \\
\hline GS 10 & $68 / 541$ & $13 \%$ & $2 / 53$ & $4 \%$ & $1 / 41$ & $2 \%$ & $71 / 635$ & $11 \%$ \\
\hline GS 1 & $9 / 272$ & $3 \%$ & $47 / 162$ & $29 \%$ & $3 / 54$ & $6 \%$ & $59 / 488$ & $12 \%$ \\
\hline GS 6 & $0 / 0$ & $0 \%$ & $11 / 91$ & $12 \%$ & $4 / 23$ & $17 \%$ & $15 / 114$ & $13 \%$ \\
\hline GS 2 & $31 / 245$ & $13 \%$ & $18 / 71$ & $25 \%$ & $0 / 46$ & $0 \%$ & $49 / 362$ & $14 \%$ \\
\hline GS 11 & $26 / 345$ & $8 \%$ & $64 / 104$ & $62 \%$ & $0 / 16$ & $0 \%$ & $90 / 465$ & $19 \%$ \\
\hline GS 7 & $0 / 0$ & $0 \%$ & $0 / 0$ & $0 \%$ & $8 / 37$ & $22 \%$ & $8 / 37$ & $22 \%$ \\
\hline
\end{tabular}

Note. GS = Graduate Student. In the columns listing numbers, the first number identifies lines of text expressing cognitive dissonance which is divided by the second number of total lines to yield the percent of dissonance. For example, Graduate Student 1 (GS 1) expressed cognitive dissonance in the interview transcript in 9 of 272 lines (3\%). GS 6 and GS 7 were not interviewed; GS 3 and GS 7 did not keep a reflection journal. Percentages are rounded up to the nearest whole number.

\section{Types Cognitive Dissonance}

Journal entries and interview transcripts provided information about how the student-clinicians perceived and resolved the different types of cognitive dissonance. With qualified instruction and supervision, only one of the eleven student data sets in this study indicated no cognitive dissonance at all, while data sets for the other ten revealed different types of cognitive dissonance. All ten expressed the perception of difficult clinical challenges.

Clinical needs. Five of the student-clinicians $(5 / 10,50 \%)$ expressed cognitive dissonance that involved challenges presented by the children's needs and behaviors in the clinical setting. Two of these student-clinicians $(2 / 10,20 \%)$ struggled with how to simultaneously provide different clinical strategies for widely diverse children's needs. For example, the difficulty and uncertainty of how to engage a child who persisted in using pictures and a child who used memory rather than actually reading. Both student-clinicians had to find alternative strategies in order to be successful with their clinical assignments. Three student-clinicians who were challenged by the clinical setting $(3 / 10,30 \%)$ struggled with how to respond to perplexing outcomes, that is, even though they used appropriate clinical strategies, the children they were teaching remained unresponsive. For example, one student-clinician was assigned to a child who would not respond to her in any way whatsoever, much less to engage in reading. 
Lack of knowledge or understanding. Three of the student-clinicians $(3 / 10,30 \%)$ expressed cognitive dissonance that involved not knowing or understanding what clinical strategies to use. For example, a struggle with the push-pull of phonics vs. meaning-based strategies in the literature, tension with her mother (an early intervention specialist) about strategies to use, fear that the child's progress would be lost, and inability to connect classroom instruction with clinical practice.

Self-doubts and shyness. Two of the student-clinicians (2/10, 20\%) expressed cognitive dissonance that involved internal self-doubts and shyness that interfered with performance of clinical skills. For example, nervousness and doubts expressed even after weeks of instruction and a self-description as a shy and anxious person.

\section{Strategies for Resolution of Cognitive Dissonance}

Eight of the ten student-clinicians $(8 / 10,80 \%)$ who expressed cognitive dissonance revealed varying levels of reflection in their data records, leaving two $(2 / 10,20 \%)$ with none. Only six of the student-clinicians $(6 / 10,60 \%)$ expressed critical thinking, leaving four $(4 / 10,40 \%)$ with none. Of those four, two revealed some level of reflection in journal entries and/or interviews and the other two revealed none. Seven student-clinicians $(7 / 10,70 \%)$ indicated low resistance to making changes in their clinical strategies, leaving three $(3 / 10,30 \%)$ indicating high resistance. All ten of the student-clinicians received supervisor guidance directly related to cognitive dissonance. Supervisors tended to give the same type and amount of guidance to all students with the exception of the one student-clinician who lacked understanding about how to use the clinical strategies. For this student the amount of guidance was intense and overwhelming. Seven of the student-clinicians $(7 / 10,70 \%)$ also sought and received guidance from peers. However, one student-clinician never sought guidance from his/her peers or supervisor.

Eight of the student-clinicians $(8 / 10,80 \%)$ wrote each week in at least one of their journals, leaving two $(2 / 10,20 \%)$ who did not do so. In addition to resolving cognitive dissonance, the eight student-clinicians demonstrated appropriate clinical procedures before the end of the literacy project. Two student-clinicians $(2 / 10,20 \%)$ who seemed to resolve dissonance only at the end of the project demonstrated no changes in clinical strategies, wrote no more than four entries in their reflection journals, with one making no entries, and neither chose to collaborate with their assigned teaching partners. Their data records indicated low perception, high resistance, lack of reflection, and lack of critical thinking.

\section{Discussion}

Planning for clinical practice in synchrony with classroom instruction and supervision requires attention to the types of cognitive dissonance students may encounter. The perception of cognitive dissonance revealed in the data records for the student-clinicians may be due to the use of the reflection and anecdotal journals, instruction to use these journals, and the supervisors' reminders to use them. However, student-clinicians made an uneven number of entries in the two types of journals and the types of entries made in the anecdotal journals sometimes belonged in the reflection journals and entries in the reflection journals sometimes belonged in the anecdotal journals. Reflections sometimes activated critical thinking, but some student-clinicians engaged in 
surface-level reflections without critical thinking, or no reflection at all. The lack of an explicit schedule for making and turning in journal entries, inconsistent reminders of their value, and erratic feedback from supervisors on the journal entries may have influenced variation in how student-clinicians used the journals. Supervisor reminders to use the journals were not given on a consistent schedule and supervisor instructions did not address how to use reflections to support critical thinking. Student-clinician dispositions to use critical thinking and resistance to making changes in their clinical strategies also varied. Those who engaged in critical thinking seemed to have a lower resistance to making changes and they successfully used a variety of clinical strategies before the end of the literacy project.

The types of cognitive dissonance identified in this study suggest the need for revision in the instruction, teaching, or clinical supervision that the student-clinicians receive. Half of the studentclinicians who experienced cognitive dissonance encountered complex and challenging children's needs in the clinical setting. This result suggests the need for anticipating additional customized support for the student-clinicians who receive these types of assignments. Strategies for accommodating these specialized needs should begin in the early stages of assessing the literacy levels of the children to whom the student-clinicians are assigned.

A third of the student-clinicians who experienced cognitive dissonance had lack of clarity about what strategies to use or a lack of understanding about how to use those strategies. This high proportion indicates a need for changes in the classroom instruction and/or the instructional guidance provided by the clinical supervisors. The other one fourth of the student-clinicians who had sustained internal self-doubts and shyness may benefit specifically from changes in the clinical instruction. Those student-clinicians had different supervisors, and only one of the supervisors provided encouragement. The other student-clinician received no encouragement, but received a load of intensive instructional guidance and criticism from her supervisor, failed to collaborate with her peers, and failed to demonstrate appropriate clinical strategies at any time during the literacy project.

The type of guidance from clinical supervisors involved a high number of prescriptive procedures. Supervisors used modeling throughout the interactions with students (Martinez, 2016) along with multiple strategies during small group sessions, shared reading sessions and Writer's Workshop. Supervisors often provided theory instruction; information about research findings; practical advice; and oral feedback, encouragement, and face-to-face consultations. When problems arose during sessions, the supervisors often took over to model the literacy activity or generated extensive clinical notes. In addition, as mentioned earlier, supervisor comments sometimes were intensely critical rather than supportive or encouraging.

Two of the student-clinicians who experienced cognitive dissonance indicated misplaced timing of classroom instruction, and that the content on the strategies to use and how to use them did not align with the actual need for their use of the information in their clinical sessions. When timing of the instruction is misplaced, students will encounter conflicts between concept knowledge and how to apply this knowledge in their clinical sessions. Additionally, if the supervisory guidance does not align with the content in the classroom instruction, the student-clinicians may not have enough prerequisite information to fully process the guidance they receive. 
For some students, cognitive load seemed to have been exacerbated by intensive instructional guidance and intensive supervisory prescriptive feedback. This cognitive load seems to have interfered with their ability to understand and use the appropriate clinical strategies. When initially learning, student-clinicians do not benefit from an avalanche of information. Difficulty increases if they do not receive the needed wait-time to reflect upon, process new information, and to learn from their mistakes.

Peer support and collaboration seems to have had a substantial positive influence for those seven student-clinicians who sought guidance from and collaborated with their peers. In spite of no evidence of critical thinking in her data records, peer support and supervisor encouragement led to success for one of the student-clinicians who had a lack of clarity about what strategies to use and had confrontations with a family member about the best strategies to use. Another student-clinician reflected on and used peer suggestions on how to overcome shyness and use literacy strategies. These expressions of self-doubt disappeared in later journal entries and the student-clinician was able to use multiple effective strategies before the end of literacy project. However, a third of the student-clinicians failed to make use of engagement with their peers.

\section{Limitations}

Several factors limit the generalizability of findings in this study. To begin, the power of critical thinking in resolving cognitive dissonance is only partially supported in this study since four of the student-clinicians had data records that did not reveal the presence of critical thinking. This omission does not mean that the students failed in thinking critically, only that the use of such thinking was not recorded in the data records. Similarly, for the two student-clinicians for whom no record was found to indicate clear reflection, it may be that they actually engaged in such reflection.

Relatedly, the field notes and recordings did not include details of observed oral feedback between sessions or during staff meetings. Collectively the type of supervision varied. For example, Supervisor A added audio comments and supplemented these with a written sheet. Most of the time, Supervisor B gave each student written guidance after the read aloud activity in front of a large group of children. Supervisor C not only gave nearly twice as much written guidance to the assigned student-clinicians, but also to the graduate students assigned to the other supervisors. In spite of this amount of guidance, data for the student-clinicians assigned to Supervisor C indicated far more dissonance. Perhaps this happened because Supervisor C was the least experienced. Or it may have been simply luck of the draw of the particular students assigned to Supervisor C. The extent of feedback suggests it is unlikely that her other duties reduced the amount of clinical supervision she could provide. It is equally possible that her supervision style was more enabling for the students to be honest.

The context of the study itself presents some limitations. One concern is that the student-clinicians entered the literacy project with uneven entry-levels. They received clinical assignments without consideration of those differences and the children with whom they were assigned had wide variations in clinical needs. Half of the student-clinicians expressed cognitive dissonance involving those clinical needs and it remains unknown as to whether the other types of cognitive dissonance expressed by the remaining half were influenced by the clinical needs of the children. 
These variations among the student-clinicians and among the children make generalizations difficult.

Finally, although this study had a rich database of information from the student-clinicians and their supervisors, the sample and size of the study was limited by the number of students participating in the literacy project. In addition, a potential source of bias derives from the initial investigator's close engagement with the literacy project and personal familiarity with the student-clinicians, supervisors, and classroom instructor in the literacy project. Both authors sought to minimize this limitation by grounding the framework for analysis in the research literature and following a reiterative protocol for coding data until both reached agreement. Results do suggest a framework for future study, but because of sample size and the particular context of the literacy project, these results cannot be generalized to the larger CSD studentclinician population, clinical supervisors, or programs.

\section{Recommendations for Programs}

The following strategic modifications should improve learning and reduce cognitive dissonance in future classroom-to-clinical practice literacy programs. These recommendations concern classroom instruction, assessment of student-clinician entry-levels, use of reflection journals, and type of clinical supervision.

Classroom instruction. The daily activities of some of the classes incorporated active learning activities and critical thinking, but theory-first characterized most of the classes. Brackenbury and colleagues (2014) suggest enhancing the signature pedagogy of CSD by including learner-centered education, evidence-based practice (i.e., service learning), clinical thinking (i.e., case studies), and collaboration with clients and colleagues (i.e., simulation exercises, role-playing, peer-teaching, clinical scenarios, discussion, and writing groups). Such learning strategies could make a curriculum "less theory first and more conducive to reflective practice" (Folkins, 2016 p. 83). Systematic course design to more closely align instructional segments with expected clinical experiences could improve the connection of content with expected clinical practice and reduce the cognitive load that interferes with learning (Ramos Holguín \& Aguirre Morales, 2014).

Student-clinician entry levels. Skills assessment, content assessment or a confidence survey could indicate when student-clinicians have low knowledge or confidence in how to apply clinical strategies (Goodson, Slater, \& Zubovic, 2015). Supervisors who know the students' entry levels would be better prepared to adapt supervision styles based on student needs. As an example, a knowledge survey could show if students have very low confidence in using the Cloze Procedure, or any other task needed for proficient clinical practice. Nuhfer and Knipp (2003) and Goodson and colleagues (2015) provide excellent examples of how to use such data to adjust the type, timing, and level of instruction.

Reflection journals. Confusion can be reduced by using only one reflection journal, rather than a separate anecdotal journal. The amount of reflection could be improved by scheduling a regular time for journal entries and systematically reinforcing the value of journal writing. Adding guiding questions could improve the quality of and help connect reflections to critical thinking (Dunlap, 2006; Moussa-Inaty, 2015). Examples of possible guiding questions could include "What 
strategies did you use in your clinical session?", "What was successful?", "What, if anything, would you change if you had a chance to do this session over again?", and "What questions do you now have, if any?"

Clinical supervision strategies. Nondirective supervision should be added to focus reflection, increase motivation for learning, and enable student-clinicians to apply their knowledge more successfully in the clinical context. Grounded in constructivism, this strategy supports the critical thinking needed when worked examples provided in classroom instruction fail to match the range of clinical needs the student-clinicians will actually encounter. Instead of relying only on prescriptive modeling, supervisors should also gradually reduce the amount of their guidance as student-clinicians become more proficient. Applying such supervision within a literacy project would engage a more collaborative transition to self-supervision (Anderson, 1988; Gordon, 1990; Harris et al., 1992).

The supervisory strategy should be designed to include the asking of probing questions. Thus, instead of telling a student what to do, a supervisor asks questions that focuses the reflection process on issues, such as key aspects of clinical strategies, oversights, what is needed for preclinic preparation, and self-critique. Skillfully framed questions can prompt student-clinicians to compare their clinical strategies to models of clinical practice, make stronger connections between classroom instruction and clinical practice, and reflect on the fit of clinical models to a specific client's needs (Martinez, 2016).

Guided questions could also help in video analysis. For example, early in the program, in response to a video record of the student attempting to apply a clinical strategy, a student could answer questions to prompt self-reflection of what the student did correctly and what requires further guidance. A later video could then be followed with questions to prompt the student to see improvement or the need for further guidance. Similar approaches to video feedback have been successful in positive self-modeling for development of professional skills (Fukkink, Trienekens, \& Kramer, 2011; Whitehead, et al., 2016) and have been found to be more effective when combined with expert feedback (Hammoud, Morgan, Edwards, Lyon, \& White, 2012).

The program design should include consistent critical, praiseworthy, and informative supervisor feedback on a regular schedule. This should enhance student-clinician motivation, reflection, understanding, and learning, and thereby, reduce cognitive dissonance and modify what students do (Orsmond, Merry, \& Reiling, 2002). For students with lower confidence levels, such support should help them to gain greater self-efficacy and improve their clinical practice.

\section{Summary}

This study provided a framework for identifying the factors of perception, resistance, difficulty, reflection, critical thinking, and guidance in identifying and resolving cognitive dissonance during the instruction-to-clinical practice experiences of CSD students in a literacy project. Using this framework, the data analysis revealed cognitive dissonance related to the complexity and types of client needs, the type and sequencing of the instruction provided to the students, student difficulties in understanding and applying clinical knowledge, the frequency and quality of reflections in journals, internal student dispositions such as shyness, and the type of supervision students 
received. Results suggest that future instruction-to-clinical practice programs should incorporate more active learning and more closely align the content of instructional segments with the needs of anticipated clinical assignments, adapt instruction to match student-clinician entry levels, make consistent use of reflection journals and add structured questions to prompt critical thinking as part of the reflection process, and incorporate nondirective supervision that makes use of probing questions to help students make stronger connections between the instruction they receive and their clinical practice assignments.

\section{References}

ASHA American Speech-Language-Hearing Association, Ad Hoc Committee on Supervision. (2013). Final Report: Knowledge, Skills, and Training Consideration for Individuals Serving as Supervisors. Retrieved from http://www.asha.org/uploadedFiles/Supervisors-KnowledgeSkills-Report.pdf

American Speech-Language-Hearing Association (n.d.). Practice Portal. [web site]. Retrieved from

https://www.asha.org/PRPSpecificTopic.aspx?folderid=8589942113\&section=Key_Issues

Anderson, J.L. (1988). The supervisory process in speech-language-pathology and audiology. Boston: Little, Brown and Company.

Atabaki, A. M. S., Keshtiaray, N., Yarmohammadian, M. H. (2015). Scrutiny of critical thinking concept. International Education Studies, 8(3), 93-102.

Barron, L. (2015). Preparing pre-service teachers for performance assessments. Journal of Interdisciplinary Studies in Education, 3(2), 68-75.

Berlyne, D. E. (1965). Structure and direction in thinking. New York: John Wiley \& Sons, Inc.

Brackenbury, T., Folkins, J. W., \& Ginsberg, S. M. (2014). Examining educational challenges in communication sciences and disorders from the perspectives of signature of pedagogy and reflective practice. Contemporary Issues in Communication Science and Disorders, 41, 70-82.

Brandes, G.M., \& Boskic, N. (2008, June). Eportfolios: From description to analysis. International Review of Research in Open and Distance Learning, 9(2), 1-17.

Burnes, B. (2015). Understanding resistance to change - building on Coch and French. Journal of Change Management, 15(2), 92-116.

Calkins, L. (1994). The art of teaching writing. Portsmouth, NH: Heinemann.

Calkins, L. (2006). A guide to the writing workshop, grades 3-5. Portsmouth, NH: First Hand.

Cane, J. E., Ferguson, H. J., \& Apperly, I. A. (2017). Using perspective to resolve reference: The impact of cognitive load and motivation. Journal of Experimental Psychology: Learning, Memory, and Cognition, 43(4), 591-610. doi:10.1037/xlm0000345

Caty, M-E., Kinsella, E. A., \& Doyle, P. C. (2014). Reflective practice in speech-language pathology: A scoping review. International Journal of Speech-Language Pathology, 17(4), 411-420. doi: 10.3109/17549507.2014.979870

Clydesdale, G. (2016). Management education: Reflective learning on human interaction. European Journal of Training and Development, 40(5), 286-301. Retrieved from http://search.proquest.com.ezproxy.library.ipfw.edu/docview/1823080369?accountid=11649

Cooper, J. (2007). Cognitive dissonance: 50 years of a classic theory. Los Angeles, CA: Sage Publications, Inc.

Corbin, J. \& Strauss, A. (2015). Basics of qualitative research: Techniques and procedures for developing grounded theory (4th ed.). Los Angeles, CA: Sage Publications, Inc. 
Council on Academic Accreditation (2017). Standards for accreditation of graduate education programs in audiology and speech-language pathology. Retrieved July 20, 2018 from https://caa.asha.org/wp-content/uploads/Accreditation-Standards-for-Graduate-Programs.pdf

Council of Academic Programs in Communication Sciences and Disorders. (2013). White paper: Preparation of speech language pathology clinical educators. Retrieved from: http://scotthall.dotster.com/capcsd/wp-content/uploads/2014/10/Preparation-of-ClinicalEducators-White-Paper.pdf

Creswell, J. (2013). Qualitative inquiry and research design: Choosing among five traditions (3rd ed.). Thousand Oaks, CA: Sage Publications, Inc.

Damico, J.S. \& Ball, M.J. (2010). Prolegomenon: Addressing the tyranny of old ideas. Journal of Interactional Research in Communication Disorders, 1(1), 1-29.

Damico, J.S., Simmons-Mackie, N., Oelschlaeger, M., Elman, R., \& Armstrong, E. (1999). Qualitative methods in aphasia research: Basic issues. Aphasiology, 13, 651-665.

Dean, K. L., \& Jolly, J. P. (2012). Student identity, disengagement, and learning. Academy of Management Learning \& Education, 11(2), 228-243.

Dunlap, J. C. (2006). Using guided reflective journaling activities to capture students' changing perceptions. TechTrends, 50(6), 20-26.

Durden, T. R., \& Truscott, D. M. (2013). Critical reflectivity and the development of new culturally relevant teachers. Multicultural Perspectives, 15(2), 73-80.

Dutton, L., \& Sellheim, D. O. (2017). Academic and clinical dissonance in physical therapist education: How do students cope? Journal of Physical Therapy Education, 31(1), 61-72. Retrieved from http://search.proquest.com.ezproxy.library.ipfw.edu/docview/1877747576?accountid=11649

Dyment, J. E., \& O'Connell, T. S. (2014). When the ink runs dry: Implications for theory and practice when educators stop keeping reflective journals. Innovative Higher Education, 39(5), 417-429. Retrieved from http://doi.org/10.1007/s10755-014-9291-6

Fani, T., \& Ghaemi, F. (2011). Implications of Vygotsky's zone of proximal development (ZPD) in teacher education: ZPTD and self-scaffolding. Social and Behavioral Sciences, 29, 15491554. Retrieved from https://www.sciencedirect.com/science/article/pii/S1877042811028631

Festinger, L. (1957, renewed 1985 by author). A theory of cognitive dissonance. Redwood City, CA: Stanford University Press

Firestone, S. E. (2004). Value change: Conscious cognitive dissonance or automated process? Dissertation Abstracts International Section A, 65, 1661.

Folkins, J. W. (2016). Are we asking the right questions about pedagogy in communication sciences and disorders? Contemporary Issues in Communication Science and Disorders, 43, 77-86.

Fukkink, R. G., Trienekens, N., \& Kramer, J. C. (2011). Video feedback in education and training: Putting learning in the picture. Educational Psychology Review, 23(1), 45-63.

Gay, G. (2010). Culturally responsive teaching: Theory, research and practice (2nd ed.). New York, NY: Teachers College Press.

Gerjets, P., Scheiter, K., \& Cierniak, G. (2009). The scientific value of cognitive load theory: A research agenda based on the structuralist view of theories. Educational Psychology Review, 21, 43-54. doc: 10.1007/s10648-008-9096-1

Glaser, E.M. (1942). An experiment in the development of critical thinking. Teachers College Record, 43(5), 409-410. 
Goodson, L. A., Slater, D., Zubovic, Y. (2015, February). Adding confidence to knowledge. Journal of the Scholarship of Teaching and Learning, 15(1), 20-37.

Gordon, S. P. (1990). Developmental supervision: An exploratory study of a promising model. Journal of Curriculum and Supervision, 5(4), 293-307.

Hammoud, M. M., Morgan, H. K., Edwards, M. E., Lyon, J. A., \& White, C. (2012). Is video review of patient encounters an effective tool for medical student learning? A review of literature. Advances in Medical Education and Practice, 3, 19-30.

Hargreaves, K. (2016). Reflection in medical education. Journal of University Teaching \& Learning Practice, 13(2), Article 6. Retrieved from http://ro.uow.edu.au/cgi/viewcontent.cgi?article=1655\&context=jutlp

Harmon-Jones, E., Harmon-Jones, C., \& Levy, N. (2015). An action-based model of cognitive dissonance processes. Current Directions in Psychological Science, 24(3), 184-189. Retrieved from http://www2.psych.ubc.ca/ schaller/308Readings/HarmonJones2015.pdf

Harris, H. F., Ludington, J. R., Ringwalt, S. S., Ballard, D. D., Hooper, C. R., Bouyer, F. G., \& Price, K. R. (1992). Involving the student in the supervisory process. National Student Speech Language Hearing Association Journal, 19, 109-118. Retrieved from http://www.asha.org/uploadedFiles/asha/publications/cicsd/1992InvolvingtheStudent.pdf

Hart, W., Albarracín, D., Eagly, A. H., Brechan, I., Lindberg, M. J., \& Merrill, L. (2009). Feeling validated versus being correct: A meta-analysis of selective exposure to information. Psychological Bulletin, 135(4), 555-588. doi:10.1037/a0015701

Hill, A. E., Davidson, B. J., \& Theodoros, D. G. (2012). Reflections on Clinical Learning in Novice Speech-Language Therapy Students. International Journal of Language \& Communication Disorders, 47(4), 413-426.

Hirsh, J. B., Galinsky, A. D., \& Zhong, C-B. (2011). Drunk, powerful, and in the dark: How general processes of disinhibition produce both prosocial and antisocial behavior.

Perspectives on Psychological Science, 6, 415-427. Retrieved from https://sites.insead.edu/facultyresearch/research/file.cfm?fid=57845

Jermias, J. (2001). Cognitive dissonance and resistance to change: The influence of commitment confirmation and feedback on judgment usefulness of accounting systems. Accounting, Organizations and Society, 26, 141-160. Retrieved from http://isiarticles.com/bundles/Article/pre/pdf/21108.pdf

Jonassen, D. (2012). Designing for decision making. Educational Technology Research and Development, 60(2), 341-359. Retrieved from http://www.jstor.org/stable/41488586

Jost, J.T. (2015). Resistance to change: A social psychological perspective. Social Research: An International Quarterly, 82, 607-636. Retrieved from https://psych.nyu.edu/jost/Resistance\%20to\%20Change_A\%20Social\%20Psychological\%20 Perspective.pdf

Lai, E. R. (2011). Critical thinking: A literature review (Research Report). Pearson. Retrieved from http://images.pearsonassessments.com/images/tmrs/CriticalThinkingReviewFINAL.pdf

Lee, S., \& Schwarz, N. (2010). Washing away post-decisional dissonance. Science, 328(5979), 709-709.

Lew, D. N. M., \& Schmidt, H. G. (2011). Writing to learn: Can reflection journals be used to promote self-reflection and learning? Higher Education Research \& Development, 30(4), 519532.

Martinez, S. A. (2016). Why are we doing this? Cognitive science and nondirective supervision in clinical teaching, 26. Kansas Journal of Law and Public Policy. Retrieved from: 
http://digitalrepository.unm.edu/law_facultyscholarship/483

McFall, J. P. (2015). Rational, normative, descriptive, prescriptive, or choice behavior? The search for integrative metatheory of decision making. Behavioral Development Bulletin, 20(1), 4559. doi:10.1037/h0101039

McGregor, I., Newby-Clark, I. R., \& Zanna, M. P. (1999). 'Remembering' dissonance: Simultaneous accessibility of inconsistent cognitive elements moderates epistemic discomfort. In E. Harmon-Jones, J. Mills, E. Harmon-Jones, J. Mills (Eds.), Cognitive dissonance: Progress on a pivotal theory in social psychology (pp. 325-353). Washington, DC, US: American Psychological Association. doi:10.1037/10318-013

McKimmie, B. M., Terry, D. J., \& Hogg, M. A. (2009). Dissonance reduction in the context of group membership: The role of metaconsistency. Group Dynamics: Theory, Research, and Practice, 13(2), 103-119. doi:10.1037/a0014554

McLeod, S. A. (2018). Cognitive Dissonance. Retrieved July 20, 2018 from https://www.simplypsychology.org/cognitive-dissonance.html

McNamee, P., \& Celona, J. (2008). Decision analysis for the professional (4th edition). SmartOrg, Inc. Retrieved from https://smartorg.com/wp-content/uploads/2011/08/Decision-Analysis-forthe-Professional.pdf

McSweeney, J. M. (2014). Reflective teaching and learning: Why we should make time to think. Teaching Innovation Projects, 4(2), Article 7. Retrieved from https://ir.lib.uwo.ca/tips/vol4/iss2/7/

Mills, J. (1999). Improving the 1957 version of dissonance theory. In E. Harmon-Jones, J. Mills, E. Harmon-Jones, J. Mills (Eds.), Cognitive dissonance: Progress on a pivotal theory in social psychology (pp. 25-42). Washington, DC, US: American Psychological Association. doi:10.1037/10318-002

Moussa-Inaty, J. (2015). Reflective writing through the use of guiding questions. International Journal Teaching and Learning in Higher Education, 27(1), 1812-9129.

Nilson, L. B. (2013). Creating self-regulated learners: Strategies to strengthen student selfawareness and learning skills. Sterling, VA: Stylus Publishing, LLC.

Nuhfer, E. \& Knipp, D. (2003). The knowledge survey: A tool for all reasons. To Improve the Academy, 21, 59-78. Retrieved April 18, 2014 from

http://www.vcu.edu/cte/workshops/teaching_learning/2007_resources/knowledge_survey.pdf

Orsmond, P., Merry, S., \& Reiling, K. (2002). The student use of tutor formative feedback in their learning. Paper presented at the Learning Communities and Assessment Cultures Conference organised by the EARLI Special Interest Group on Assessment and Evaluation, University of Northumbria, 28-30 August 2002. Retrieved from http://www.leeds.ac.uk/educol/documents/00002233.htm

Palloff, R.M., and Pratt, K. (2007). Building online learning communities: Effective strategies for the virtual classroom. San Francisco, CA: John Wiley \& Sons, Inc.

Panadero, E. \& Alonso-Tapia, J. (2014). How do students self-regulate? Review of Zimmerman's cyclical model of self-regulated learning. Anales de Psicología, 30(2), 450-462.

Patrick, J. H. (1986). Critical thinking in the social studies. ERIC Digest No. 30 [On-line]. Retrieved from: https://www.ericdigests.org/pre-924/critical.htm

Pychyl, T.A. (July 22, 2011). Agency, responsibility and autonomy: An existential perspective on procrastination as self-regulation failure. Paper presented at the $7^{\text {th }}$ biennial conference of Counseling the Procrastinator in the Academic Context, Amsterdam, The Netherlands.

Ramos Holguín, B., \& Aguirre Morales, J. (2014). Materials development in the Colombian 
context: Some considerations about its benefits and challenges. $H O W, 21(2), 134-150$. Retrieved from https://howjournalcolombia.org/index.php/how/article/view/8/160

Rauch, A. G., \& Scheming, M. S. (2010). Linking cognition to cognitive dissonance through scientific discrepant events. Systemics, Cybernetics and Informatics, 8(5), 17-21.

Roberson, S. (2017). Learning for maximum impact: Four critical but overlooked ideas. Education, 137(3), 283-296.

Rolls, G. P. (2015). Classic Case Studies in Psychology: Third Edition. Hove, East Sussex: Routledge.

Sawchuk, S. (2013). Combined measures better at gauging teacher effectiveness, study finds. Education Week, 32(17), 1-16.

Sinclair, A. (2009). Provocative pedagogies in e-learning: Making the invisible visible. International Journal of Teaching and Learning in Higher Education, 21(2), 197-212. Retrieved from https:/files.eric.ed.gov/fulltext/EJ899306.pdf

Solis, R. (2015). Teachers' experiences of learning through a reflective inquiry process focused on the relationship between teaching beliefs and behaviors (Order No. 3725349). Available from ProQuest Dissertations \& Theses Global. (1712381063). Retrieved from https://digital.library.txstate.edu/bitstream/handle/10877/5544/SOLIS-DISSERTATION2015.pdf;sequence $=1$

Stone, J., \& Focella, E. (2011). Hypocrisy, dissonance and the self-regulation processes that improve health. Self Study and Identity, 10(3).

Strayhorn, T. L. (2006). Frameworks for assessing learning and development outcomes. Retrieved from: http://nau.edu/Student-Affairs/_Forms/FALDO/

Tillard, G. D., Cook, K., Gerhard, D., Keast, L., \& McAuliffe, M. (2018). Speech-language pathology student participation in verbal reflective practice groups: Perceptions of development, value and group condition differences. Teaching and Learning in Communication Sciences \& Disorders, 2(2), Article 5.

Tolsgaard, M. G., Kulasegaram, K. M., \& Ringsted, C. V. (2016). Collaborative learning of clinical skills in health professions education: The why, how, when and for whom. Medical Education, 50(1), 69-78. doi:10.1111/medu.12814

Van Merriënboer, J. J. \& Sweller, J. (2005). Cognitive load theory and complex learning: recent developments and future directions. Educational Psychology Review, 17(2), 147-177.

Vygotsky, L. S. (1978). Mind in society: The development of higher psychological processes. Cambridge, MA: Harvard University Press.

Walton, J. D. (2011). Dissonance in the critical classroom: The role of social psychological processes in learner resistance. College Student Journal, 45(4), 769-786.

Wass, R. \& Golding, C. (2014). Sharpening a tool for teaching: The zone of proximal development. Teaching in Higher Education, 19(6), 671-684. doi:10.1080/13562517.2014.901958

Whitehead, I. J., Phillips, A. W., Bookless, L. R., Matthan, J., Madhavan, A., Nesbitt, C. I., \& Stansby, G. (2016). Direct expert involvement is not required for providing effective video feedback in the acquisition of clinical skills: A randomized trial. BMJ Simulation and Technology Enhanced Learning, 2(A3). doi: http://dx.doi.org/10.1136/bmjstel-2016-000158.7

Wicklund, R. A. \& Brehm, J. W. (1976). Perspectives on cognitive dissonance. Hillsdale, NJ: Lawrence Erlbaum Associates, Inc.

Wong, A. (2009). Cognitive Dissonance: A comprehensive review amongst interdependent and independent Cultures. The Journal of Educational Thought (JET)/Revue De La Pensée Éducative, 43(3), 245-257. Retrieved from http://www.jstor.org/stable/23765479 
Wright, S. M., Rutgers, E. M., Daly, S. R., Jablokow, K. W., \& Yilmaz, S. (2015). Exploring the effects of problem framing on solution shifts: A case study. Industrial Design Conference Presentations, Posters and Proceedings. 11. Retrieved from https://lib.dr.iastate.edu/industrialdesign_conf/11/

Yeasmin, S. \& Rahman, K. F. (2012). 'Triangulation' research method as the tool of social science research. Bangladesh University of Professionals Journal, 1(1), 154-163. 


\section{Appendix}

Examples of data records.

\section{Graduate Student's Reflection Journal}

"I was surprised by [child's] reading level (to say the least). If anything, I learned to never assume that grade level and parent reports are truly reflective of reading abilities and always be prepared for the least expected situation." [Recorded by graduate students after their clinical sessions with the children.]

\section{Graduate Student's Anecdotal Journal}

"The use of low quality miscues indicate [the child] focuses primarily on graphophonemic and less on meaning... he did use pictures to make meaning, but added details to his retelling from the pictures that had not been read yet..." [Recorded by graduate students after their clinical sessions with the children.]

\section{Clinical Observation Field Note}

"[Graduate Student's] group finished early and she had misbehavior and problems transitioning group to silent sustained reading. See her personal journal entry, videotape." [Recorded by principal investigator (first author).]

\section{Supervisor Written Feedback}

(Supervisor A) "This is a child who is very reluctant and sensitive to failure. You seem to have connected well in your folder making session. Tough to stay silent and give chance to use strategies, but note that she stays engaged."

(Supervisor B) “ and others at the edge of the group are not attending as readily. You can address that by proximal shifts - move towards those who are restless - show them the pictures and then you can get them back in."

(Supervisor C) "I love this activity — great use of your theme-great engagement — everyone has a role and is using the text for learning."

\section{Supervisor Interview Transcription}

"I went into the summer feeling that I knew a lot more about the writing process than I had in any other year. So I highlighted some things in those mini lessons differently because of that. I think initially, when we were first ready to have them sit and write, my entire objective is just to do some writing aloud with them, but it's also a way to think aloud for the students, for the reading buddies." 


\section{Supervisor Daily Feedback}

“Don't plan a whole book for you to read to her (if you did)...We need to spend a majority of her time reading. Much lower level reading materials next time...She is an aspectual reader-she is not concentrating on meaning..." [Recorded by each student's assigned supervisor.]

\section{Special Supervisory Feedback from Class Instructor}

“...this child is in complete control of this session....read my earlier comments on setting and maintaining expectations... reach her (mainly through think-alouds as modeling) to use imagery..." [Recorded by the class instructor.]

\section{Graduate Student Interview Transcription}

"Well, at the beginning I started out, um, I was really nervous about the first group —I didn't know what to do, like I was thinking of a million different things I could try...I asked pretty much everyone I know..." [Recorded by principal investigator (first author).]

\section{Graduate Student Shared Reading Transcription}

"Hooray for Fly Guy-remember where he's a football player? Want to start with that one?" [Child] (looking at pictures of different Fly Guy book covers on the back cover) "not this one, and not this one, and not this one" [Recorded by principal investigator (first author).] 